\title{
COMPETÊNCIAS E HABILIDADES DO PROFESSOR GESTOR: atribuições no modelo multicampi
}

\author{
LINA MARIA BRANDÃO DE ARAS \\ Universidade Federal da Bahia (UFBA). Doutorado em História Social, Universidade \\ de São Paulo, Professora do Programa de Pós-graduação em História e do Programa \\ de Pós-graduação em Estudos Interdisciplinares sobre Mulheres, Gênero e Feminismo. \\ ORCID: 0000-0003-0654-9777. E-mail: laras@ufba.br
}

\begin{abstract}
ANA CLAUDIA PACHECO DE ANDRADE
Universidade do Estado da Bahia (UNEB). Mestre em Literatura e Diversidade Cultura - Universidade Estadual de Feira de Santana, Professora do Curso de Licenciatura em Letras, Língua Portuguesa e Literaturas, Campus V/UNEB, Grupo de Pesquisa Políticas Públicas e gestão escolar: aspectos sócioculturais e contemporaneidade. ORCID: 0000-0002-1991-203X. E-mail: acandrade@uneb.br
\end{abstract}

\section{LUZINETE GAMA DE OLIVEIRA}

Universidade do Estado da Bahia (UNEB). Mestre em Gestão e Tecnologias Aplicadas à Educação (GESTEC/UNEB); Graduada em Biologia pela Universidade Estadual de Pernambuco (UPE); Coordenadora da Auditoria de Controle Interno da UNEB.

Pesquisadora do Grupo de Pesquisa Educação, Universidade e Região - EduReg/UNEB. ORCID: 0000-0002-8780-8314. E-mail: lgoliveira@uneb.br 


\section{COMPETÊNCIAS E HABILIDADES DO PROFESSOR GESTOR: atribuições no modelo multicampi}

O artigo ocupa-se de evidenciar as habilidades pertinentes ao professor universitário que, ao longo da sua carreira, ocupa posições administrativas na Instituição de Educação Superior (IES). O interesse pelo tema está no fato de as autoras possuírem atuação na graduação, pós-graduação e extensão, e experiência em gestão universitária. $\mathrm{O}$ tema tem sido bem aceito nas discussões referentes à gestão, considerando que há uma disponibilidade maior de produções que versam sobre gestão escolar, o que evidencia a necessidade de se tratar o tema no universo da educação superior e que permite problematizar: faz-se necessário um perfil específico de professor gestor para atender ao modelo multicampia? A pesquisa delimita o professor gestor, em especial, o diretor de departamento e toma como campo de estudo a Universidade do Estado da Bahia (UNEB), fazendo, quando necessário, um diálogo com outras IES baianas: Universidade Estadual de Feira de Santana (UEFS), Universidade Estadual do Sudoeste da Bahia (UESB) e Universidade Estadual de Santa Cruz (UESC). A opção por esta instituição deve-se ao fato de, no conjunto, possuir natureza multicampi, em um total de vinte e quatro, enquanto a UESB possui dois campis. O objetivo do artigo consiste em evidenciar que, mesmo com experiência no ensino, na pesquisa e na extensão, é também exigido dos docentes o conhecimento da área administrativa que os habilite para o exercício da gestão. A metodologia adotada é pesquisa de natureza descritiva e abordagem qualitativa baseada em bibliografia, legislação e documentação pertinente ao funcionamento da IES. A pesquisa conclui demostrando que, o fato de a UNEB ser de natureza multicampi, possui um modelo de gestão próprio, de forma a atender a esta sua característica, o que implica no desenvolvimento de habilidades específicas para o professor gestor com o propósito de promover o desenvolvimento das funções da universidade de forma eficaz e eficiente.

Palavras chave: Gestão Universitária. Professor Gestor. Habilidades e Competências.

\section{PROFESSOR MANAGER'S SILLS AND EXPERTISE: assignments at multi campi model}

The article is about skills to the university professor who, throughout his career, occupies administrative positions in the University. The interest in this subject goes in the fact that the authors have experience in education and university management. The theme has been well accepted in the discussions regarding management, considering there are articles that deal with school management, which highlights the need to discuss about graduation education management. Thefore, our research problem is: is it necessary to have a specific managing professor profile to attend a multi-campi University needs? The research delimits managing professor, especially the departments manager of the Universidade do Estado da Bahia (UNEB), making, when necessary, a dialogue with other State University, at Bahia: State Universidade Estadual de Feira de Santana (UEFS), Universidade Estadual do Sudoeste da Bahia (UESB) and Universidade Estadual de Santa Cruz (UESC). The option for this institution is due to the fact that it multi-campus, in a total of twenty-four, while the UESB has two campuses. The objective of the article is to show that, even with experience in teaching, research and extension, professors are also required to have knowledge of administration that enables them to exercise management. The methodology adopted is descriptive research and a qualitative approach based on bibliography, legislation and documentation pertinent to the functioning of the University. The research conclusion shows as UNEB is multi-campus it has its own management model in order to meet this characteristic. This implies the development of specific skills for the managing professor with the purpose to get designed results in ongoing improvements effectively and efficiently.

Keywords: University Management. Managing Teacher. Skills and Competences. plupais 


\section{COMPETENCIAS Y HABILIDADES DEL GESTOR UNIVERSITARIO: atribuciones en el modelo multicampi}

El artículo trata de resaltar las habilidades pertinentes para el profesor universitario que, a lo largo de su carrera, ocupa puestos administrativos en la Institución de Educación Superior (IES). El interés en el tema radica en el hecho de que los autores tienen experiencia en cursos de pregrado, posgrado y extensión, y experiencia en gestión universitaria. El tema ha sido bien aceptado en las discusiones sobre gestión, considerando que hay una mayor disponibilidad de producciones que se ocupan de la gestión escolar, lo que destaca la necesidad de abordar el tema en el universo de la educación superior y que permite la problematización: es necesario ¿Un perfil específico de gerente de maestros para cumplir con el modelo multicampia? La investigación delimita al profesor gerente, en particular, al director del departamento y toma como campo de estudio la Universidade Estadual da Bahia, haciendo, cuando sea necesario, un diálogo con otras IES bahianas: Universidade Estadual de Feira de Santana (UEFS), Universidade Estadual del Suroeste de Bahia (UESB) y Universidad Estadual de Santa Cruz (UESC). La opción para esta institución se debe al hecho de que, en su conjunto, tiene una naturaleza multicampi, en un total de veinticuatro, mientras que UESB tiene dos campus. El objetivo del artículo es mostrar que, incluso con experiencia en la enseñanza, la investigación y la extensión, también se requiere que los profesores tengan conocimiento del área administrativa que les permitirá ejercer la gestión. La metodología adoptada es una investigación de naturaleza descriptiva y un enfoque cualitativo basado en bibliografía, legislación y documentación relevante para el funcionamiento de la IES. La investigación concluye demostrando que el hecho de que UNEB es de naturaleza multicampi tiene su propio modelo de gestión para cumplir con esta característica, lo que implica el desarrollo de habilidades específicas para el profesor gerente con el fin de promover el desarrollar funciones universitarias de manera efectiva y eficiente.

Palabras clave: Gestión Universitaria. Profesor Gerente. Habilidades y Competencias. 


\section{COMPETÊNCIAS E HABILIDADES DO PROFESSOR GESTOR: atribuições no modelo multicampi}

\section{Introdução}

Considera-se haver uma relação entre os termos administração e gestão e que o primeiro se aplica às funções de planejar, organizar, dirigir e controlar, enquanto o segundo consiste nas funções da administração sendo desempenhada pelo líder junto a sua equipe motivada. A gestão voltada para a educação, em especial à instituição de ensino superior pública, objeto de análise do presente estudo, chama à atenção o contexto vivenciado pela sociedade brasileira, uma vez que as universidades se encontram atreladas às mudanças político-culturais e demandas próprias do nosso tempo, buscando um diálogo produtivo com a comunidade a que serve. Com base nessa compreensão, pensar as habilidades e competências de um gestor professor implica reconhecer aspectos essenciais para o bom funcionamento da instituição no que se refere à oferta de cursos de graduação, atividades de pesquisa e extensão, bem como programas de pós-graduação, em unidades acadêmicas, na Universidade do Estado da Bahia (UNEB) denominados departamentos. Tais aspectos são fundamentais para a sustentabilidade da instituição e que não podem ser desvinculados de um processo que inclui um saber administrativo.

Isto significa que o professor gestor opera uma alteração em sua atividade para além da docência, pois passa a exercer outra função, a de gestor, e que lhe impõe outra postura. Em razão disso, professores gestores assumem uma responsabilidade a mais: a de viabilizar ações referentes ao sistema de ensino, sustentadas em um conjunto de teorias desenvolvidas e legitimadas tanto no campo pedagógico e acadêmico, quanto na área da administração.

Sendo assim, este estudo busca identificar as habilidades e competências necessárias ao professor gestor no exercício de diretor de departamento da UNEB, de modo que esteja capacitado a desenvolver ações no ambiente da instituição de educação superior pública, cada vez mais, afinadas com a legislação pertinente. Ao lado desta condição está o fato de que, quando o professor assume a gestão, tem ao seu lado uma equipe de servidores comprometidos com os mesmos objetivos visando o alcance de uma educação de excelência.

\section{plupais}


A compreensão destes aspectos assume relevância por expor a necessidade de preservar o processo de autonomia nas universidades públicas. É sabido que muitos problemas ocorridos nas instituições universitárias demonstram relação com questões de ordem administrativa, o que resulta muitas vezes em dificuldades no que se refere ao atendimento de demandas e que, consequentemente, exige ações assentadas em melhor planejamento. Isto posto, a apropriação de conhecimentos específicos da administração para uma gestão universitária mais eficaz, revela que o professor gestor, visando a meta de formação de profissionais e da produção do conhecimento cientifico, diferentemente de uma empresa (cujo foco da gestão reside na produtividade e lucro), deve estar atento para desenvolver competências de gestor a fim de melhor conduzir o processo de decisões para efetivação das funções da universidade.

Em atenção ao questionamento formulado e ao objetivo geral estabelecido, este artigo tem como fundamentação teórica os seguintes tópicos: conhecimentos e habilidades necessárias ao professor gestor; as diretrizes para atuação do gestor, com ênfase a Lei de Diretrizes e Bases da Educação Nacional, LDB n ${ }^{\circ}$ 9.394/1996 e da Lei Estadual nº 8352/2002, Estatuto do Magistério Público das Universidades; e a estrutura e funcionamento da universidade multicampi.

Com este fulcro, o estudo faz uma exposição sobre habilidades necessárias ao professor-gestor, segue com a indicação de diretrizes norteadoras do trabalho do gestor, prossegue com uma análise das implicações da gestão em uma instituição multicampi a partir do caso da UNEB e conclui evidenciando as especificidades inerentes aos desafios identificados na gestão para atender a multicampia.

\section{PROFESSOR GESTOR: habilidades na área administrativa}

Este ponto se ocupa de uma exposição sobre habilidades concernentes à administração para desenhar o perfil necessário ao professor gestor em uma instituição de educação superior (IES). É fato que o professor é especialista na área de conhecimento em que atua na função docente, considerando as diversas grandes áreas de conhecimento de acordo com o Conselho Nacional de Desenvolvimento Científico e Tecnológico (CNPq), a saber: Ciências Exatas e da Terra, Ciências Biológicas, Engenharias, Ciências da Saúde, Ciências Agrárias, Ciências Sociais Aplicadas, Ciências Humanas, Linguística, Letras e Artes. No que tange à gestão, nem sempre possui as competências e 
habilidades pertinentes a planejar, organizar, dirigir, controlar, avaliar e motivar a equipe - funções básicas de um gestor.

A gestão da Universidade é uma questão complexa em todos os seus aspectos: em decorrência dos objetivos de formar profissionais, participar da construção da cidadania e do desenvolvimento social; as funções que desempenha simultaneamente de ensino, pesquisa e extensão; os profissionais com os quais a instituição atua, especialistas nas diversas áreas de conhecimento; a tecnologia que concebe e utiliza; e o modelo de estrutura organizacional e de decisão colegiada que adota. Esses são alguns dos fatores, aparentemente, de fácil compreensão, contudo, muitas vezes de difícil padronização, utilizando como referência outras organizações existentes na sociedade (FINGER, 1988).

Assim, a este professor gestor cabe a responsabilidade de lidar e decidir quanto a iniciativas de ensino, pesquisa e extensão, envolvendo docentes, técnicos administrativos, alunos, perspectivas da sociedade, recursos orçamentários e financeiros, tecnologias, dentre outros. Bem como há que se considerar que, diante das inúmeras transformações, exige-se dos atores desse processo novas habilidades e competências, pertinentes ao processo de gestão de uma unidade educacional, situada em uma sociedade em constantes mudanças.

Neste trabalho, competência é entendida como um conjunto "de conhecimentos, habilidades e atitudes interdependentes e necessárias à consecução de determinados propósitos." (Durand, 1998, p. 03, apud ANDRADE; STRAUHS, 2006). Ou seja, ter o conhecimento e ser capaz de diagnosticar a situação, identificar possíveis estratégias, escolher a que melhor atenda e agir.

A habilidade diz respeito à capacidade de desenvolver uma ação. Na gestão concebem-se três tipos básicos de habilidades, a saber: habilidades técnicas, que expressam o saber utilizar métodos, técnicas e equipamentos no exercício da função; habilidades humanas, as quais dizem respeito à aptidão de se comunicar, motivar, coordenar, liderar, solucionar conflitos em sua equipe de trabalho; e habilidades conceituais, relacionadas à predisposição em ter iniciativa, ideias, conceitos, de pensar e propor soluções com visão de futuro (LACOMBE; HEILBORN, 2008).

Para o entendimento das habilidades e competências do gestor cabe evidenciar que gestão corresponde ao conjunto de atividades realizadas por uma equipe coordenada e motivada por um

\section{plurais}


líder, ou seja, o gestor. A ação de gerir exige requisitos básicos a exemplo de: um conjunto de funções; desempenho de papeis; competências de conhecimento, perspectiva e atitudes; e emprego de habilidades conceituais, humanas e técnicas. Na universidade integrante da esfera pública, todos estes itens referentes às funções, papéis e competências estão relacionados ao cumprimento das atividades da administração pública, se encontram em consonância com os princípios da burocracia descritos por Weber (SILVA, 2001).

Lacombe e Heilborn (2008), à luz de Katz (1974), sintetizaram as habilidades necessárias ao gestor, ao pressupor que o administrador seria alguém que dirige as atividades de outras pessoas e assume a responsabilidade de atingir determinados objetivos por meio da soma de esforços. Os autores ressaltam que a suposição de que exista um tipo característico de gestor adequado aos diversos tipos, tamanhos e estruturas de organizações, é amplamente aceita.

Recorrendo à perspectiva de Tofik (2013), este chama a atenção quanto ao desafio do gestor contemporâneo, do qual são requeridos: liderança, sabedoria, coragem e determinação. Desta forma, o papel do professor gestor é transfigurado, saindo da perspectiva puramente pedagógica e acadêmica para ocupar o lugar e o espaço de um líder, gestor de políticas vinculadas à educação superior, de recursos e de procedimentos pedagógicos, acadêmicos e administrativos.

Assim, o professor gestor, no exercício do cargo e função de diretor de uma instituição universitária, ênfase deste estudo, deverá conhecer e refletir acerca das demandas contemporâneas para a educação em decorrência dos atributos da sociedade caracterizada como a sociedade do conhecimento, da tecnologia e comunicação. Também ao domínio das diretrizes legais e dos parâmetros relevantes do âmbito do direito educacional e das políticas e diretrizes para a organização e o funcionamento da universidade, acrescenta-se, ainda, a legislação concernente à execução orçamentária e financeira e de gestão de pessoas, neste caso docentes, técnicos administrativos e terceirizados.

Nessa direção, a universidade pública como estrutura autárquica deverá obedecer aos fundamentos da administração pública, conforme previsto na Constituição Federal de 1988, competindo-lhe observar os princípios da legalidade, impessoalidade, moralidade, publicidade e eficiência. Em relação à gestão pública, esta deve culminar também no cumprimento dos objetivos institucionais previstos nos seus documentos institucionais tais como Plano de Desenvolvimento Institucional

\section{plurais}


(PDI) e Plano Plurianual (PPA), objetivos estes viabilizados por meio de programas internos de gestão. Deve, ainda, atender aos regramentos da legislação federal e estadual que regulam a educação superior, bem como aos que regulam a execução do orçamento público. A esse respeito, Esther (2011) registra que à ótica da gestão organizacional, as competências gerenciais têm adentrado na gestão pública, especialmente das universidades. Há também que se ressaltar sua ampla função social, do empoderamento da comunidade acadêmica e o seu papel de conscientização da sociedade civil, que fazem parte da natureza da ação.

\section{UNIVERSIDADE PÚBLICA: diretrizes para atuação do gestor}

Segundo a Lei $\mathrm{n}^{\circ} 9.394$ de 20 de dezembro de 1996, que estabelece as leis e diretrizes da educação nacional, no seu artigo 21, inciso II; um dos níveis da educação escolar é a educação superior. Como este texto se ocupa do estudo de uma instituição pública, recorrendo à mesma lei, o artigo 19 estabelece sobre as categorias administrativas das instituições de ensino, sendo que o inciso I advoga que "públicas, assim entendidas as criadas ou incorporadas, mantidas e administradas pelo Poder Público" e, no caso do Estado da Bahia, a educação superior mantida pelo poder público é formada por quatro universidades na condição de autarquias, vinculadas à Secretaria Estadual de Educação: Universidade Estadual de Feira de Santana (UEFS), Universidade Estadual de Santa Cruz (UESC), Universidade Estadual do Sudoeste da Bahia (UESB) e Universidade do Estado da Bahia (UNEB), esta última que ocupa a análise aqui desenvolvida.

No aspecto que interessa para a presente análise, a gestão, no artigo 56 a Lei de Diretrizes e Bases da Educação (LDB) estabelece que:

Artigo 56. As instituições públicas de educação superior obedecerão ao princípio da gestão democrática, assegurada a existência de órgãos colegiados deliberativos, de que participarão os segmentos da comunidade institucional, local e regional.

De posse de uma compreensão de gestão, ao referir-se a órgãos colegiados deliberativos, merece destaque o parágrafo único do artigo 56 indicando aspectos que interessam para a presente análise:

\section{plurais}


Em qualquer caso, os docentes ocuparão setenta por cento dos assentos em cada órgão colegiado e comissão, inclusive nos que tratarem da elaboração e modificações estatutárias e regimentais, bem como da escolha de dirigentes.

O inciso evidencia o que chamamos de atores no processo de gestão das IES, os docentes. Neste caso não restam dúvidas sobre as responsabilidades dos docentes para a existência das universidades. A lei é clara ao determinar a porcentagem de setenta por cento dos docentes com a tarefa perante os órgãos colegiados e comissões. Esta participação ganha maior responsabilidade quando são detalhadas as atribuições desses docentes no que diz respeito à legislação interna pertinente a estatutos, regimentos e escolha dos seus dirigentes.

Considerando que o objeto de estudo é professor gestor, quando se trata de gestão a LDB n 0394/1996 contempla a educação básica, em termos de denominar a presença de profissionais para a realização das tarefas de direção e coordenação pedagógica. No entanto, pode-se inferir que a autonomia da universidade não exige que a lei estabeleça quem será este profissional, uma vez que já indica que $70 \%$ do corpo docente deverá se responsabilizar por tarefas administrativas.

O que a mencionada LDB enfatiza a respeito do ensino superior é a exigência de titulação do corpo docente, no artigo 66, devendo ser "prioritariamente em programas de mestrado e doutorado", condição inerente às funções da universidade em relação à pesquisa e produção do conhecimento. $\mathrm{Na}$ educação básica, por exemplo, o parágrafo $2^{\circ}$ do artigo 67 é claro ao afirmar que:

São consideradas funções de magistério as exercidas por professores e especialistas em educação no desempenho de atividades educativas, quando exercidas em estabelecimento de educação básica em seus diversos níveis e modalidades, incluídas, além do exercício da docência, as de direção de unidade escolar e as de coordenação e assessoramento pedagógico.

Significa que a legislação maior da educação prevê, entre as atividades educativas, além da docência, o cargo de direção, coordenação e assessoramento pedagógico. Isso tem relação com o que se anunciou anteriormente a respeito do fato de que há uma disponibilidade significativa de produções e publicações em relação à gestão escolar, voltada para a educação básica.

Observadas essas questões gerais presentes na LDB n ${ }^{\circ}$ 9394/1996, como o objeto de estudo é o perfil do professor gestor, verifica-se o que prevê a Lei Estadual n ${ }^{\circ} 8.352$, de 02 de setembro 
de 2002 que dispõe sobre o Estatuto do Magistério Público das Universidades do Estado da Bahia, visando indagar a esta lei específica sobre a gestão nas universidades estaduais baianas.

Para a questão em tela, o documento, ao tratar das atividades do magistério superior, no artigo $3^{\circ}$ estabelece que, nas Universidades mantidas pelo Estado da Bahia, entende-se por atividades de magistério superior, precisamente o inciso II: "as inerentes ao exercício de direção e assessoramento na administração acadêmica". Claro que a lei é fiel ao que a tradição sempre reconheceu como atividades de magistério superior, o que está exposto no inciso I: "as pertinentes à pesquisa, ensino e extensão que, indissociáveis, sirvam à aprendizagem, à produção do conhecimento, à ampliação, difusão e comunicação do saber".

Como o objeto de interesse é a gestão em âmbito geral, área acadêmica e área administrativa, o artigo $4^{\circ}$ é ilustrativo ao definir como "[...] as atividades de direção, assessoramento e chefia, relacionadas com órgãos e funções acadêmicas da administração universitária." Para melhor fundamentar a questão de estudo, evidencie-se os parágrafos nos quais a citada Lei Estadual $n^{\circ}$ 8.352/2002 esclarece os cargos e funções da administração acadêmica que são de responsabilidade dos docentes universitários, sendo: Reitor, Vice-Reitor, Pró-Reitor da Área Acadêmica, Diretor de Departamento, Coordenador de Colegiado de Curso e Outros inerentes à área acadêmica,

Esta estrutura é seguida pelas quatro universidades estaduais baianas, deixando estabelecido que as funções da natureza administrativa podem ser ocupadas por servidores técnico-administrativos, a exemplo das Pró-Reitorias de Gestão e Desenvolvimento de Pessoas, Administração, Planejamento e Infraestrutura. De outra forma, os cargos e funções da área acadêmica são privativos dos docentes, a saber: Ensino de Graduação, Pesquisa e Ensino de Pós-graduação e Extensão. Mesmo que haja diferença na denominação dessas Pró-Reitorias entre as universidades, a respeito desses cargos, a lógica é a mesma, os cargos da área acadêmica só podem ser ocupados por docentes.

Observe-se, a seguir a situação de cada uma das universidades estaduais baianas a respeito do funcionamento administrativo quando se trata da figura do professor gestor.

A UEFS foi instituída pela Lei Delegada no 12, de 30 de dezembro de 1980, como sucessora da Fundação Universidade de Feira de Santana, criada pela Lei no 2.784, de 24 de Janeiro de 1970, com sede e foro na cidade de Feira de Santana. Com uma administração central representada pelos

\section{plurais}


órgãos superiores Conselho de Administração (CONSAD), Conselho Universitário (CONSU) e Conselho Superior de Ensino, Pesquisa e Extensão (CONSEPE), com representação entre outros atores, dos docentes, segue na sua estrutura com as Pró-Reitorias, unidades de desenvolvimento organizacional e unidades universitárias constituídas por Departamentos de Ensino, Pesquisa e Extensão e Colegiados de Cursos. Trata-se de uma IES com oferta das suas atividades no campus localizado na cidade de Feira de Santana, contando com nove departamentos, o que já a diferencia da organização e funcionamento da UNEB, com trinta departamentos distribuídos em 24 campi.

A Universidade Estadual de Santa Cruz (UESC) foi criada pela Lei $\mathrm{n}^{\circ} 6.344$, de 05 de dezembro de 1991, e reorganizada pela Lei $N^{0} 6.898$, de 18 de agosto de 1995. Teve sua origem nas escolas isoladas criadas no eixo Ilhéus/Itabuna, na década de sessenta. Em 1972, resultante da iniciativa das lideranças regionais e da Comissão Executiva do Plano da Lavoura Cacaueira (CEPLAC), as escolas isoladas (Faculdade de Direito de Ilhéus, Faculdade de Filosofia de Itabuna, e Faculdade de Ciências Econômicas de Itabuna) congregaram-se, formando a Federação das Escolas Superiores de Ilhéus e Itabuna (FESPI).

Assim como a UESC, tem modelo unicampi composto por dez departamentos, localizada entre os municípios de Ilhéus e Itabuna. A sua organização administrativa é constituída por órgãos de administração superior; órgãos de administração setorial; órgãos de apoio administrativo e órgãos suplementares. Considerando a participação de docentes como gestores, é importante salientar que a administração Superior é formada pelo CONSU e CONSEPE. A administração Setorial é composta pelos Departamentos e Colegiados de Curso. Quanto aos órgãos de apoio administrativo e órgãos Suplementares que fazem parte da estrutura administrativa da UESC, não foi alcançado por esse estudo, pois podem ser ocupados por técnicos e não são privativos de docentes.

Em termos de natureza multicampi como a UNEB, faz parte da estrutura da educação superior do Estado da Bahia, a Universidade Estadual do Sudoeste da Bahia (UESB), instituída pela Lei Delegada n. ${ }^{\circ}$ 12, de 30 de dezembro de 1980, autorizada pelo Decreto Federal n. ${ }^{\circ}$ 94.250, de 22 de abril de 1987. Considerando a estrutura multicampi, conforme define o artigo $6^{\circ}$ do Regimento Geral da UESB, prevê que:

A Universidade adotará regime de administração compatível com a necessidade do funcionamento dos seus Órgãos e Departamentos, incorporando princípios de descentralização, sem prejuízo da unidade acadêmico-administrativa, a fim de atender às peculiaridades de sua configuração territorial e do modelo multicampi. 
De acordo com o Regimento geral da UESB, artigo $7^{\circ}$, a estrutura organizacional é constituída pelos órgãos: Administração Superior, formada por Órgãos Deliberativos, Órgão Curador e Órgão Executivo; Administração Setorial, desdobrado em: órgãos deliberativos setoriais e órgãos executivos setoriais; e órgãos suplementares.

É constituída por três campi: Campus Universitário de Vitória da Conquista, em Vitória da Conquista, composto por 10 (dez) departamentos; Campus Universitário de Jequié, no município de Jequié, contando com 05 (cinco) departamentos; e Campus Universitário Juvino Oliveira, em Itapetinga, composto por 03 (três) departamentos.

Finalmente a UNEB, universidade na qual está centralizado o estudo: a Universidade do Estado da Bahia foi criada pela Lei Delegada n. ${ }^{\circ}$ 66, de $1^{\circ}$ de junho de 1983, reconhecida pela Portaria Ministerial n. ${ }^{\circ}$ 909, de 31 de julho de 1995 e resultante da integração de faculdades da capital, Salvador, incluindo o Centro de Ensino Técnico da Bahia (CETEBA) e do interior.

Entre as universidades mantidas pelo Governo do Estado da Bahia é a que tem abrangência maior em termos físicos estando presente em todas as regiões do Estado constituindo-se em 24 campi e 30 departamentos que ofertam cursos de graduação e de pós-graduação nas mais diversas áreas do conhecimento.

De acordo com o art. $8^{\circ}$ do Regimento Geral, a gestão da UNEB possui a seguinte estrutura organizacional:

- Órgãos Deliberativos de Administração Superior, conceituados pelo Conselho Universitário (CONSU), Conselho Superior de Ensino, Pesquisa e Extensão (CONSEPE), Conselho de Administração (CONSAD);

- Órgãos Executivos de Administração Superior, representado pela Reitoria, composta pelas Pró-Reitorias;

- Órgãos Deliberativos de Administração Setorial, compostos pelos Conselhos de Departamento e Colegiados de Curso;

- Órgãos executivos da Administração Setorial, as Diretorias de Departamentos;

\section{plurais}


- Órgãos Suplementares;

- Órgãos de Apoio Acadêmico-Administrativo.

Conforme o artigo $7^{\circ}$ do Regimento Geral "a Estrutura acadêmico-administrativa da UNEB tem como base os Departamentos e é composta pela Reitoria e Órgãos que respondem pelas atividades indissociáveis de ensino, pesquisa e extensão [...]”. Pode-se compreender que, apesar da complexidade da sua estrutura, considerando os diferentes órgãos, o Departamento, diferente do que acontece nas outras Universidades Estaduais da Bahia, é a base da organização acadêmica da UNEB. Como órgão executivo da administração setorial, o Departamento, na estrutura administrativa da UNEB, é Constituído por dois órgãos: o Conselho de Departamento com função deliberativa e a Direção do Departamento, função executiva.

Ressalte-se que a base orgânica em departamentos das quatro instituições aqui apresentadas decorre da promulgação da Lei Estadual n. ${ }^{0}$ 7.176, de 10 de setembro de 1997, que reestruturou as quatro universidades e estabeleceu em seu artigo $2^{\circ}$ que:

As Universidades Estaduais da Bahia, integrantes do Sistema de Educação Superior, ficam constituídas pelos cursos atualmente em funcionamento, sem prejuízo de outros que venham a ser criados, adotando a estrutura orgânica com base em Departamentos, a serem estabelecidos em ato regulamentar.

Cabe ainda registrar que a Lei Estadual $\mathrm{n}^{\circ}$ 13.466, de 22 de dezembro de 2015 revogou a Lei Estadual n. ${ }^{\circ} 7.176 / 97$, quando dispõe no Artigo $4^{\circ}$, que a “organização e o funcionamento das atividades acadêmicas e administrativas das Universidades serão estabelecidos por Estatuto Jurídico Especial, para atender a suas peculiaridades." Contudo, complementa no Artigo 13: "enquanto não forem editados os Estatutos de que trata o artigo $4^{\circ}$ desta Lei, fica mantida a atual organização administrativa e acadêmica das Universidades Estaduais da Bahia." Até a data de elaboração deste artigo, as alterações em estatuto das referidas instituições não sofreram alterações, portanto permanece a mesma estrutura, apesar de revogada da Lei Estadual n. ${ }^{\circ}$ 7.176/97.

Na UNEB, os Departamentos, diferentemente das outras três instituições estaduais baianas, são os responsáveis pelo desempenho da área finalística da universidade, acadêmica e pedagógica, bem como pela gestão dos recursos orçamentários e financeiros, mediante a descentralização de 
crédito orçamentário à respectiva unidade gestora - unidade responsável por administrar dotações orçamentárias e financeiras próprias ou descentralizadas vinculada ao departamento -, a seguir caracterizada.

O Departamento é, também, responsável pela elaboração do seu plano de execução anual, onde se encontram relacionadas às ações e metas previstas para realização no exercício, bem como o recurso disponível. Observa-se, desta maneira, que o Departamento, na UNEB, participa do processo de planejamento, indicando o que vai fazer e de quanto precisa, e não apenas recebe os recursos que a Reitoria repassa para que possa desenvolver suas ações.

Esta estrutura organizacional, na qual a administração superior (Conselhos Superiores e Pró-Reitorias) e a administração setorial (departamentos) são responsáveis pela gestão acadêmica, pedagógica, orçamentária e financeira, é a opção da UNEB no sentido de assegurar que todos os seus campi tenham recursos orçamentários e financeiros para desenvolver as ações finalísticas.

Neste caso, destaca-se a figura da direção do departamento, órgão da administração setorial que só poderá ser ocupado por um docente com assento nos dois dos dois conselhos superiores CONSU e CONSEPE. Para melhor compreensão do seu papel, cita-se o artigo 62 do Regimento Geral (RG) da IES, que, define:

O Departamento é o órgão de Administração Setorial, pertencente à estrutura universitária, que congrega docentes, técnico-administrativos e discentes, sendo responsável pelo planejamento, execução, acompanhamento, controle e avaliação das atividades didático-científicas e administrativas, gozando de autonomia nos limites de sua competência.

De acordo com o Art. 10 da Resolução CONSU n. ${ }^{\circ}$ 888, de 06 de maio de 2012, em consonância com a referida Lei Estadual n. ${ }^{\circ}$ 8352/2002, a gestão de uma unidade de ensino é de competência apenas do segmento docente. A sua nomeação à função decorre de mandato eletivo pelo período de dois anos, podendo ser prorrogado por igual período. Os requisitos para a candidatura ao cargo de Diretor de Departamento, além de ser integrante da carreira do magistério superior da UNEB, de acordo com o artigo 10 da referida resolução são:

\section{plurais}


I - integrar o quadro permanente da UNEB, após o cumprimento do estágio probatório;

II - ser lotado no respectivo Departamento;

III - estar em efetivo exercício do magistério, em sala de aula ou exercendo atividades privativas do docente, como prevê a Lei Estadual $n^{\circ} 8352 / 2002$; IV - possuir formação mínima de pós-graduação lato sensu;

V - não ultrapassar a idade limite para efeito de aposentadoria compulsória antes da integralização do mandato;

VI - residir na cidade sede do Departamento ou em município localizado em até $200 \mathrm{~km}$ de distância.

Sendo o foco da pesquisa a figura do professor gestor, o próprio RG explicita as exigências do ocupante deste cargo na estrutura acadêmico-administrativa da UNEB. Como se pode observar, os requisitos estão relacionados com aspectos funcionais, exceto quando faz referência à formação mínima exigida (inciso IV do artigo 10) e prática para exercício do cargo (inciso VI do artigo 10). No entanto, já atendendo às exigências do artigo 10, para além das exigências funcionais não faz referência à experiência em cargo de gestão ou que o candidato tenha formação na área de gestão.

Neste caso, o docente, atendendo aos requisitos previstos no artigo 10 da Resolução CONSU n ${ }^{\circ} 888 / 2012$, sendo eleito e empossado no cargo de Diretor, terá que fazer a gestão de instâncias e setores que, de acordo com o artigo 66 do RG fazem parte da estrutura do Departamento:

Artigo 66. O Departamento tem a seguinte estrutura:

I - Gabinete da Direção:

a) Secretaria da Direção;

b) Assessoria da Direção;

c) Protocolo.

II - Colegiado de Curso:

a) Secretaria de Colegiado.

III - Coordenação Administrativa:

a) Grupo de Trabalho de Recursos Humanos;

b) Grupo de Trabalho de Almoxarifado e Patrimônio; 
c) Grupo de Trabalho de Serviços Gerais.

IV - Coordenação Orçamentária, Financeira e Contábil;

V - Coordenação Acadêmica:

a) Secretaria Acadêmica.

VI - Coordenação de Biblioteca;

VII - Coordenação de Tecnologia da Informação e Comunicação (TIC);

VIII - Coordenação de Laboratórios;

IX - Núcleo de Pesquisa e Extensão (NUPES):

a) Secretaria.

Constata-se que, além dos aspectos didático-pedagógicos previstos no inciso V do artigo 66, ou seja, aqueles relativos ao ensino de graduação, pós-graduação, nas modalidades presencial e À distância; pesquisa e extensão, estão, de acordo com $\S 2^{\circ}$ do artigo 10 , os aspectos administrativos, assim discriminados:

I - quanto aos recursos humanos: quantificação e qualificação do pessoal docente e técnico-administrativo;

II - quanto aos recursos financeiros: acréscimos orçamentários para cobertura de projetos e atividades;

III - quanto aos recursos materiais: dimensionamento físico do espaço, instalações, equipamentos e materiais de consumo.

Em atenção ao mencionado anteriormente, no âmbito da UNEB, o professor gestor, neste caso o diretor, congrega todas as funções previstas no Estatuto e Regimento Geral e Regimento Interno, desde a gestão acadêmica, política, de pessoal, execução administrativa, orçamentária e financeira. Cada Departamento possui uma Unidade Gestora (UG) conceituada, conforme Instrução Normativa da Superintendência de Administração Financeira, SAF n 20, de 9 de agosto de 2017, como unidade administrativa investida do poder de gerir e executar recursos orçamentários e financeiros, próprios ou descentralizados, podendo também efetuar atividades de execução contábil e patrimonial da despesa pública. Nesse contexto, o diretor gestor figura como Ordenador da Despesa, definido pelo Decreto-Lei n ${ }^{\circ}$ 200, de 1967 como "toda e qualquer autoridade de cujos atos resultarem emissão de empenho, autorização de pagamento, suprimento ou dispêndio".

\section{plurais}


O docente, ao ingressar no papel de gestor de Departamento, recebe a delegação de competência, conferida pelo Reitor e exercida na forma da lei, do Estatuto e Regimento Geral. O diretor de Departamento exerce duas funções no nível executivo, como Diretor do Departamento e, no nível deliberativo, como presidente do Conselho de Departamento. Observa-se, no entanto, que as formas de ingresso do docente no quadro de servidores da instituição busca assegurar a mensuração das suas competências e habilidades relacionadas, prioritariamente, para o exercício enquanto docente, no cumprimento de atividades finalísticas (ensino, pesquisa e extensão). Ratifica-se, assim, que esses processos não estabelecem como critérios de avaliação para o ingresso saberes ligados ao domínio de atividades administrativas, com as quais o docente pode se deparar quando assume o papel de gestor universitário.

Com esta estrutura complexa para atender a sua multicampia não é de estranhar que se apresentem para o professor gestor das diferentes unidades desafios que comportam pensar habilidades e competências para além daquelas exigidas para o gestor de uma IES com uma estrutura mais concentrada, aspecto tratado no ponto a seguir.

\section{Gestão na multicampia da UNEB e suas particularidades (complexidades)}

A análise proposta nesta seção requer que reconheçamos a multicampia como uma particularidade que implica em complexidade da gestão. Estando organizada no modelo de multicampi e multirregional, a UNEB é administrada de forma descentralizada. Uma das formas de expressão da descentralização é a sua presença em 19 dos 27 Territórios de Identidade nos quais está dividido o Estado da Bahia, para efeito de planejamento, o que reforça a necessidade de se pensar a sua gestão considerando particularidades desta abrangência social.

Renald Legendre (1993, p.1397), no seu dicionário de educação, define Universidade multicampi como "compreendendo várias constituintes situadas em localidades diferentes" e toma como exemplos a Universidade do Quebec (UQ) e a Universidade de New York (SUNY). Assim, no âmbito da gestão universitária, o termo aparece não só para distinguir a sua espacialidade (multicampi), ou abrangência de ação, mas, também, para caracterizar a universidade moderna, a multiversidade, como denominou Clark Kerr (1982). A configuração multicampi é reforçada por essa multiversidade de ações, tendo em vista que a localização em espaços distintos oportuniza a interação com várias comunidades externas e, assim, atende a um número maior de pessoas. 
A universidade multicampi é entendida como a matriz de um tipo de instituição universitária composta por muitos campi, propiciando a desconcentração administrativa e dispersão físico-geográfica, com reflexo nas dimensões acadêmicas, organizacionais e espaciais, sendo vários campi localizados em um só município ou em diferentes municípios. (FIALHO, 2005).

Salienta-se aqui a fala do idealizador da UNEB, professor Edivaldo Boaventura, explicitando que a "localização dessas faculdades em centros urbanos do interior se apresentava sumamente significativa para que se criasse uma universidade com pluralidade de campi." (BOAVENTURA, 2009, p. 31).

\begin{abstract}
Acresce a isso que tinha bem presente em mente a maneira como se comportava a educação superior estadual em face do espaço, das exigências de formação de quadros, especialmente, para o ensino. Além de tudo, o que mais me motivava era voltar o ensino superior para o interior no atendimento à demanda de educação universitária nos principais centros urbanos da Bahia. [...] (BOAVENTURA, 2009, p. 32).
\end{abstract}

A referida dispersão, dentre outros aspectos, diz respeito às relações entre regiões geográficas e centros urbanos, aos diversos cenários históricos, culturais, educacionais, sociais, econômicos, demográficos, em decorrência das diferentes regiões onde os campi estão instalados, exigindo da instituição uma articulação entre os fatores externos e o que é construído no seu ambiente interno. Este cenário se constitui no ambiente de atuação do professor gestor, o diretor de departamento da UNEB.

Outro aspecto que se relaciona com o modelo multicampia a ser considerado é trazido por Zabalza (2007, p. 77), quando expressa que "as cidades disputam o privilégio de ter uma universidade, e os diferentes grupos sociais veem nela um sinal de prestígio (porém não qualquer universidade e qualquer tipo de curso, mas os que têm a melhor 'marca social')". Como afirmado por Fialho (2005, p 116.), a universidade:

[...] na sua essência, é responsável para pensar outros fenômenos, a exemplo o processo da re(produção) social que lhe originou e interfere na sua atuação como a todos os demais fenômenos à sua volta, potencializados pela sua abrangente competência para, em resumo, lidar com fatos do conhecimento, da história e da ciência.

\title{
plurais
}


Não restam dúvidas dos desafios que se apresentam para a gestão de uma IES de modelo multicampi, a partir das suas particularidades e complexidades que se apresentam para a gestão como desafios. Tendo como foco para a gestão universitária, a figura da direção do departamento, cargo que somente poderá ser exercido por docentes, implica em responsabilidade do professor gestor assumida como agente público e cidadão ao comprometer-se com o alcance dos objetivos da instituição no cumprimento da sua missão junto à sociedade.

Em relação à competência e atribuição de professores gestores com enfoque regimental, Green (2000) ressalta duas dimensões de competências, as individuais e as organizacionais. Conforme o autor, estas representam o conjunto de conhecimentos técnicos e habilidades do gestor que possuem mecanismos diretamente relacionados aos objetivos da organização. No caso do professor gestor, nos limites da Universidade do Estado da Bahia, constituída por unidades universitárias distribuídas em diversos municípios da região favorecendo a interiorização do ensino superior, os conhecimentos são de natureza acadêmica, administrativa, orçamentária e financeira.

O modelo de gestão adotado pela UNEB sinaliza complexidades que requer adaptações para o próprio funcionamento da instituição visto que o trato de questões administrativas está implicado na observação de distintas realidades, considerando a presença em diferentes Territórios de Identidade.

\section{Considerações}

O título do artigo já remete a aspectos relevantes da gestão, habilidades e competências sem, no entanto, pretender se estender para outros temas da administração como motivação e criatividade. Considerando que no contexto atual as IES devem estar comprometidas não apenas com a formação de profissionais e a produção de conhecimento mas, também, com o ambiente externo, o que inclui as avaliações externas para recredenciamento; cada vez mais faz-se necessário pensar a gestão universitária na perspectiva desse cenário. Cenário esse em que, além de pensar conhecimento e a sua produção, apropriação e socialização, outros elementos se impõem, a exemplo de tecnologia e inovação.

Considerando ainda que ao se falar de gestão tem-se que buscar os aportes teóricos e principio lógicos da administração, quando este texto definiu por pensar a gestão universitária, reconheceu as peculiaridades na estruturação para desenvolvimento das atividades da organização universitária. Levou-se em conta, ainda, as implicações profissionais das suas autoras e tomou como objeto as universidades estaduais da Bahia, com ênfase na Universidade do Estado da Bahia evidenciando a sua multicampia. 
Tendo essas considerações acima como norteadoras, cabe ainda ressaltar que a UNEB, uma vez adequada às transformações atuais e em um diálogo com as necessidades locais e regionais, ao ter sua organização estruturada em departamentos, responsáveis pelas ações pedagógicas, acadêmicas, administrativas, orçamentárias e financeiras, tem nesta forma uma maneira de repercutir positivamente sobre a realidade local operando transformações significativas numa determinada comunidade e seu entorno, e modificando deste modo a paisagem educacional, econômica e social do lugar/território.

A universidade integrante da administração pública deverá obedecer aos fundamentos da administração pública conforme previsto na Constituição Federal competindo-lhe observar os princípios da legalidade, impessoalidade, moralidade, publicidade e eficiência. De igual modo, a UNEB deve alcançar seus objetivos, previstos nos documentos institucionais tais como PDI, PPA e seus programas internos de gestão, observando o que dispõem as legislações Federal e Estadual que regulam a educação superior, orçamento público e os aspectos administrativos.

Assim, do professor gestor, neste estudo o diretor de departamento, é esperado conhecer e refletir acerca das demandas contemporâneas para a educação e as características da sociedade do conhecimento. Também é previsto o domínio das diretrizes legais e dos parâmetros relevantes do âmbito do direito educacional e das políticas e diretrizes para a organização e o funcionamento da universidade, mais especificamente de uma unidade universitária, o departamento. Este se constitui no perfil específico de professor gestor para atender ao modelo multicampi da UNEB.

Acredita-se que, ao analisar aspectos relacionados com habilidades e competências para a gestão universitária, alguns temas se esboçam e evidenciam importância, apesar de não ter sido o foco do estudo. Referem-se a dilemas comuns das universidades como organizações, a gestão e o conhecimento, pois aí se impõem dois sentidos: um voltado para o ensino, a pesquisa e a extensão e o outro se refere à gestão das funções das universidades.

\section{REFERÊNCIAS}

ANDRADE, Murilo Martins de; STRAUHS, Faimara. R. Competências Requeridas pelos Gestores de Instituições de Ensino Superior Privadas: um Estudo em Curitiba e Região Metropolitana. In: Revista Gestão Industrial. V. 02, n. 03. Ponta Grossa, PR. Universidade Tecnológica Federal do Paraná (UTFPR), 2006. p. 87-102. Disponível em < https://periodicos.utfpr.edu.br/ revistagi/article/view/106/103>. Acesso em: 01 março 2020.

\section{plurais}


BAHIA. Lei $\mathbf{N}^{\mathbf{0}} \mathbf{7 . 1 7 6}$, de 10 de setembro de 1997. Reestrutura as Universidades Estaduais na Bahia.

BAHIA. Lei $\mathbf{N}^{0} \mathbf{1 3 . 4 6 6}$, de 22 de dezembro de 2015. Dispõe sobre a organização e funcionamento das Universidades Estaduais da Bahia, revoga a Lei nº 7.176, de 10 de setembro de 1997, e dá outras providências.

BAHIA. Lei Estadual $\mathbf{n}^{\mathbf{0}}$ 8352, de 02 de setembro de 2002. Dispõe sobre o Estatuto do Magistério Público das Universidades.

BOAVENTURA, Edivaldo Machado. A Construção da Universidade Baiana: origens, missões e afrodescendência. Salvador: EDUFBA, 2009.

BRASIL. Lei $\mathbf{n}^{\mathbf{0}}$ 9394/96, de 20 de dezembro de 1996. Estabelece as diretrizes e bases da Educação Nacional. Brasília: MEC, 1996. Disponível em < http://www.planalto.gov.br/ccivil_03/ leis/19394.htm $>$. Acesso em: 15 dezembro 2019.

BRASIL. Decreto-lei No 200, de 25 de fevereiro de 1967. Dispõe sobre a organização da Administração Federal, estabelece diretrizes para a Reforma Administrativa e dá outras providências. Disponível em $<$ http://www.planalto.gov.br/ccivil 03/decreto-lei/del0200.htm>. Acesso em: 15 fevereiro 2020.

ESTHER, Angelo Brigato. As competências gerenciais dos reitores de universidades federais em Minas Gerais: a visão da alta administração. Cadernos EBAPE.BR, 9 (spe1), 2011. p. 648-667. Disponível em: $<$ https://dx.doi.org/10.1590/S1679-39512011000600011>. Acesso em: 20 Jan. 2020.

FIALHO, Nadia Hage. Universidade Multicampi. Brasília: Plano Editora, 2005. 128p.

FINGER, Almeri Paulo, Gestão Acadêmica In: FINGER, Almeri P. (Org.). Universidade: Organização e Planejamento. Florianópolis: UFSC/CPGA/NUPEAU, 1988. p. 71-88.

GREEN, Paul C. Desenvolvendo competências consistentes: como vincular sistemas de recursos humanos a estratégias organizacionais. Rio de Janeiro: Qualitymark, 2000.

KERR, Clark. Os usos da Universidade. Fortaleza: UFC, 1982. p. 19-36.

LACOMBE, Francisco José Masset; HEILBORN, Gilberto Luiz José. Administração:

Princípios e Tendências. 2. ed. rev. e atualizada. São Paulo: Saraiva, 2008.

LEGENDRE, Renald. Dictionnaire actuel de l'éducation. Montréal: Guérin, 1993. 


\section{SECRETARIA ESTADUAL DA FAZENDA DO ESTADO DA BAHIA. Instrução Normativa} SAF $\mathbf{N}^{\circ} \mathbf{2 0}$, de 9 de agosto de 2017, que estabelece procedimentos para as inclusões, alterações e exclusões no Esquema de Unidades Gestoras utilizado no Sistema Integrado de Planejamento, Contabilidade e Finanças do Estado da Bahia - Fiplan. Disponível em $<\underline{\text { https: } / / \text { www.sefaz. }}$ ba.gov.br/administracao/pdf_saf/IN_SAF_020_unidades\%20gestoras.pdf $>$. Acesso em: 15 fevereiro 2020.

SILVA, Reinaldo Oliveira da. Teorias da Administração. São Paulo: Pioneira Thompson Learning, 2001.

TOFIK, Denise Sawaia. A gestão acadêmica nas instituições de ensino superior. In.: COLOMBO, Sonia Simões (org.). Gestão universitária: os caminhos para a excelência. Porto Alegre: Penso, 2013. p. 104-116.

UNEB. Regimento geral da Universidade do Estado da Bahia. Disponível em $<$ https:/portal. uneb.br/conselhos/wp-content/uploads/sites/103/2019/02/Regimento-Geral-da-UNEB-1.pdf> Acesso em: 15 dezembro 2019.

UNIVERSIDADE DO ESTADO DA BAHIA. Resolução CONSU n. ${ }^{\mathbf{0}} \mathbf{8 8 8}$, de 06 de maio de 2012.

ZABALZA, Miguel, A. O ensino universitário: seu cenário e seus protagonistas. São Paulo: Artmed, 2002.

Enviado em: 30 de março de 2020.

Inserido em: 20 de abril de 2020.

Esta obra está licenciada com uma Licença Creative Commons Atribuição 4.0 Internacional. 